\title{
Mid-Infrared Sources for Biomedical Applications Based on Chalcogenide Glass Fibres
}

\author{
Angela B. Seddon ${ }^{1}$, Slawomir Sujecki ${ }^{1}$, Lukasz Sojka ${ }^{2}$, David Furniss ${ }^{1}$, Zhuoqi Tang ${ }^{3}$, David \\ Mabwa $^{1}$, Joel Nunes ${ }^{1}$, Richard Crane ${ }^{1}$, Harriet Parnell ${ }^{4}$, Dinuka Jayasuriya ${ }^{5}$, Meili Shen ${ }^{1}$, Yuanrong \\ Fang $^{1}$, Sendy Phang ${ }^{1}$, Elżbieta Bereś-Pawlik ${ }^{1}$, Emma Barney $^{1}$, Mark Farries ${ }^{1}$, Trevor Benson* ${ }^{1}$ \\ ${ }^{1}$ George Green Institute for Electromagnetics Research, Faculty of Engineering, University of \\ Nottingham, University Park, Nottingham, UK \\ ${ }^{2}$ Telecommunications and Teleinformatics Department, Wroclaw University of Technology, \\ Wroclaw, Poland \\ ${ }^{3}$ Fibercore Ltd., Southampton, UK \\ ${ }^{4}$ ANSYS Granta, Cambridge, UK \\ ${ }^{5}$ Thorlabs Ltd, Cambridge, UK
}

\begin{abstract}
Many important molecules show strong characteristic vibrational transitions in the mid-infrared (MIR) part of the electromagnetic spectrum. This leads to applications in spectroscopy, chemical and bio-molecular sensing, security and industry, especially over the mid- and long- wave infrared atmospheric transmission windows of 3-5 $\mu \mathrm{m}$ and 8-13 $\mu \mathrm{m}$.

In this paper, we review some of our more recent experimental and simulation work aimed at developing new light sources based on chalcogenide glass optical fibres that can help us utilize this spectral region for biomedical applications. This includes the development of supercontinuum and bright luminescent sources and our progress towards fibre-based lasers. We place these developments in the context of MIR imaging and spectroscopy in order to show how they bring the promise a new era in healthcare and clinical diagnostics.
\end{abstract}

Keywords: Mid-infrared imaging and spectroscopy, chalcogenide glasses, fibre optics, supercontinuum generation (SCG), luminescent sources, fibre lasers.

\section{INTRODUCTION}

This paper reviews some of our recent work developing mid infrared (MIR) sources for biomedical applications based on chalcogenide glass fibres. The portion of the electromagnetic spectrum of the mid infrared spectral region from 1.5 to 12 $\mu \mathrm{m}$ contains strong characteristic absorption peaks associated with the vibrational transitions of many important molecules. These afford 'fingerprint' spectroscopy based on the recognition of molecular 'signatures' in MIR radiation after it has interacted with a material. Whilst the present motivation for our work is biomedical imaging and sensing, wherein the MIR radiation interacts with tissue, MIR spectroscopy has many other industry (e.g. process monitoring, pollution monitoring) and defence (e.g. detection of explosives) applications. Work performed under the EU-funded Minerva (MId-to NEaR infrared spectroscopy for improVed medical diAgnostics) project [www.Minerva-project.eu], in which The University of Nottingham was a partner, made great progress towards developing MIR technology to improve the early diagnosis of cancer. This included the production and characterisation of various low loss chalcogenide glass fibres, both undoped and doped with rare earth ions towards MIR fibre lasers, and the prediction and subsequent demonstration of supercontinuum generation at wavelengths extending beyond $13 \mu \mathrm{m}$. Our work has contributed to the rapid progress that has been made worldwide in developing mid infrared optics over the last decade; this embraces the

development of commercial MIR optical components, including quantum cascade lasers, low-loss chalcogenide-fibre $(1.5-10 \mu \mathrm{m})$, fibre combiners/splitters (1.5-6.5 $\mu \mathrm{m})$ (IRflex Corp), mercury-cadmium-telluride (MCT) photodetectors (2$11 \mu \mathrm{m})$ (ThorLabs), source pigtailing, etc. Low- loss, compact, MIR planar integrated photonics technologies have also emerged; these include silicon-on-sapphire [1], germanium-on-silicon (Ge-on-Si) [2], sub-wavelength suspended silicon 
[3] and chalcogenide glasses [4, 5]. Moreover, there has been extensive work to realise both broad- and narrow-band fibre-based light sources at wavelengths up to around $4 \mu \mathrm{m}$ in tellurite and fluoride (especially fluoroindate) glasses [6, 7]

This invited review paper is structured as follows. After this brief introduction, Section 2 introduces chalcogenide glasses, and reviews some of the properties which influence the use of these glasses as hosts for the development of both broad- and narrow-band MIR sources. Section 3 then briefly overviews some contributions towards broad-band (supercontinuum) sources and Section 4 describes the introduction of trivalent lanthanide (rare earth) ions into chalcogenide glasses as a means for achieving narrow-band sources. Finally, some brief conclusions are drawn.

\section{CHALCOGENIDE GLASSES}

Chalcogenide glasses contain the chalcogen elements sulfur, selenium and tellurium from Group 16 of the Periodic Table, combined with elements from Groups 14 and 15 (e.g. arsenic, antimony or germanium). They offer flexibility in composition and hence refractive index (which ranges from around 2.2 for germanium arsenic sulfides to over 3.4 for glasses with large tellurium concentrations), large optical non-linearity, optical transmission over large windows that cover the MIR and the ability to dope with optically active trivalent lanthanide (rare earth) ions. The bulk transmission of sulphide glasses extends out to wavelengths around $10 \mu \mathrm{m}$, that of selenide glasses to around $16 \mu \mathrm{m}$ and of telluride glasses out to about $20 \mu \mathrm{m}[8,9]$. The short wavelength cut-off transparency edge of chalcogenide glasses corresponds to the optical bandgap. This is at visible wavelengths for Ge-As-S glasses, in the near infrared for Ge-As-Se compositions and in the MIR for Ge-As-Se-Te glasses. Work at Nottingham to take advantage of these promising materials has included extensive materials preparation and characterisation, including purification to reduce unwanted losses, the development of compositions to allow active rare earth doping, the fabrication of both single composition ('unstructured'), step index and micro-structured fibres, and the development of tapered fibres tips for scanning nearfield infrared microscopy (SNIM) at MIR wavelengths application of these glasses in the development of MIR light sources requires glasses demands the development of compositions offering low phonon energy, chemical stability, the possibility for drawing fibre and resistance to crystallisation. The development of narrow band sources based on the incorporation of trivalent lanthanide ion dopants within the glass calls additionally for compositions with good dopant solubility and high absorption and emission cross-sections. The experimental work has been supported by extensive numerical modelling and electromagnetic simulation founded on experimentally derived materials parameters.

Experimental techniques used to assess the optical properties of chalcogenide glasses include Fourier transform infrared spectroscopy (FTIR) absorption measurements on both bulk glass samples and fibres. Further measurements on lanthanide doped glasses include photoluminescence spectrum and photoluminescence lifetime measurements; these have been undertaken on both bulk and fibre samples. Refractive index, and very often its behaviour over a range of wavelengths, is another key parameter that influences optical design. Since glasses of the same nominal composition yet different density can form depending on the cooling rate through the glass transition region, it is reasonable to conclude that the refractive index of chalcogenide glasses depends not only on their composition, but also on their processing conditions, e.g. thermal history. Techniques developed and used by us for measuring the refractive index of chalcogenide glass compositions synthesised in Nottingham, and their temperature dependence, are summarised in [10]

All the above measurements reveal the key material properties that are required for supportive optical modelling and simulation work.

Additional physical characterisation of the glasses reveals important information such as composition (EDX), crystallisation (XRD), onset glass transition temperature ( $\mathrm{Tg}$ ) and an assessment of viscosity- temperature behaviour that is used to determine glass preform extrusion and fibre drawing conditions and which once again provides key information simulation activities that support the experimental work [11,12].

\section{SUPERCONTINUUM GENERATION}

Fibre-based supercontinuum (SC) sources $[13,14]$ can provide multi-octave frequency bandwidth in combination with high brightness, fibre delivery and single-mode output. The high non-linear refractive index and broad transmission windows of chalcogenide glasses can be exploited in MIR supercontinuum generation (SCG). The work described in 
[15], which was undertaken with DTU and others as part of the Minerva project, demonstrated MIR SCG in chalcogenide-glass step index fibres (SIF). These SIFs had been designed to produce both ultra-high numerical aperture (NA) and thermal compatibility of the core and cladding glasses; they were fabricated using a multi-stage extrusion and preform-drawing process. In the experimental demonstration intense ultra-short pulses with a central wavelength of either $4.5 \mu \mathrm{m}$ or $6.3 \mu \mathrm{m}$ were launched into short pieces of the SIF. These generated a MIR supercontinuum spanning 1.5 $\mu \mathrm{m}$ to $11.7 \mu \mathrm{m}$ and $1.4 \mu \mathrm{m}$ to $13.3 \mu \mathrm{m}$, respectively that was confined by the core of the fibre. This extended the then state-of-the art $1-4.75 \mu \mathrm{m}$ spectral SC range obtained from fluoride or tellurite fibres where the long-wavelength limit is dictated by material absorption. There is a significant current research effort focused on extending the wavelength coverage towards the mid-Infrared (Mid-IR) in the 2 to $20 \mu \mathrm{m}$ molecular fingerprint region using various chalcogenide glass compositions. Our recent work with DTU has included studies of supercontinuum sources based on the Ge-As-SeTe glass system [16]. The aim was to exploit the highest nonlinearity and longest transmission wavelength edge in the chalcogenide glass family offered by Te-based glasses. Low-loss $\mathrm{Ge}_{16} \mathrm{As}_{24} \mathrm{Se}_{15.5} \mathrm{Te}_{44.5}(\mathrm{at} . \%) / \mathrm{Ge}_{10} \mathrm{As}_{23.4} \mathrm{Se}_{66.6}$ (at.\%) SIFs were successfully modelled and fabricated. These possessed an ultra-high NA of $\sim 1.88$. SC generation from fibres with several core diameters was investigated when pumped with a $\mathrm{kW}$ peak power source delivering $250 \mathrm{fs}$ pulses at $4.65 \mu \mathrm{m}$ wavelength with a pulse repetition rate of $20.88 \mathrm{MHz}$. The broadest MIR SC achieved was $1.5-11.6 \mu \mathrm{m}$ with total output power of $6.5 \mathrm{~mW}$, corresponding to an estimated launched peak power of $1.5 \mathrm{~kW}$. It was concluded that future distillation of the cladding glass should further lower the fibre loss at longer wavelengths where the fundamental mode has a significant overlap with the cladding $(\sim 31 \%$ cladding overlap at $12 \mu \mathrm{m}$ wavelength for the $4 \mu \mathrm{m}$ core fibre) and that this could lead to further spectral extension. Simulation work has also proposed new designs to shift the zero-dispersion wavelength (ZDW) of non-silica fibres towards shorter wavelengths [17].

\section{LUMINESCENT SOURCES}

Chalcogenide glasses can act as a low-phonon energy hosts for active trivalent lanthanide (rare earth) ion dopants such as Pr, Tb, Dy, Ho, Er, Tm, Yb, Ce and Sm. These can produce near-infrared (NIR) and MIR PL emissions - and are thus promising candidates for realising bright, inexpensive, and robust MIR light sources [18-19]. These lanthanide cations possess several absorptions from their respective ground states [20] but, as described later, they can also exhibit multiple excited state absorption (ESA) bands. Trivalent gallium or indium should be added to the chalcogenide glasses to act as a solubiliser for the lanthanide ions [21].

Important fundamental studies have investigated the effect of doping level, the chemical form in which the dopant is added and the percentage of solubiliser in the composition on key glass properties such as crystallisation, solubility, impurity levels and the local environment of the lanthanide ions. The dopant level and the percentage of solubiliser in the glass composition must be chosen carefully to avoid unwanted crystallisation [22-24]. The rare earth metals and metallic compounds used to introduce the dopant can bring undesirable hydride, oxide, hydroxide and water contaminants, with associated MIR absorption bands. The chalcogenide-selenide host glass system provides the current benchmark for rare earth ion doped chalcogenide glass fibres [25-26]. The fabrication of a SIF with small core of $500 \mathrm{ppmw} \mathrm{Pr}^{3+}-\mathrm{doped} \mathrm{Ge}-$ A-s-Ga-Se and a Ge-As-Ga-Se-S optical cladding glass is described in [26]. The measured absorption spectra of $\mathrm{Pr}^{3+}-$ doped Ge-As-Ga-Se glasses reveal an absorption band spanning the wavelength range from 3.5 to over $6 \mu \mathrm{m}$. This band contains contributions from both the electronic $\operatorname{Pr}^{3+}$ absorption and $\mathrm{H}-\mathrm{Se}$ impurity absorption in the glass; a technique to remove the effect of the impurity absorption in order to reveal the correct lanthanide absorption cross-section was described in [27]. It should be noted that the 3.5- $6 \mu \mathrm{m}$ wavelength spontaneous emission in $\operatorname{Pr}^{3+}$ doped chalcogenide glasses has been reported in range of $\mathrm{Pr}^{3+}$ - doped chalcogenide glasses by several groups, see for example [28-33].

The 3.5- $6 \mu \mathrm{m}$ emission from $\mathrm{Pr}^{3+}$ ions can be attributed to contributions from several overlapping electronic transitions. $\mathrm{Pr}^{3+}$ - doped chalcogenide glasses are appealing because readily available NIR diode lasers or active silica glass fibres can provide ground state pumping sources at wavelengths around 1.0, 1.5 and $2 \mu \mathrm{m}$. Recently, a $\mathrm{Pr}^{3+}$-doped selenide chalcogenide spontaneous emission fibre source operating in the wavelength range from 3.5 to $8 \mu \mathrm{m}$ was demonstrated at output power levels of at least $1 \mathrm{~mW}$ [34]. The multimode single material (unstructured) fibre of diameter around $400 \mu \mathrm{m}$ was pumped with commercially available laser diodes operating at $1.470 \mu \mathrm{m}, 1.511 \mu \mathrm{m}$ and $1.690 \mu \mathrm{m}$. This MIR spontaneous emission fibre source offers a viable alternative to broadband MIR supercontinuum fibre sources for molecular sensing applications. Lifetime measurements confirmed that the room temperature emission observed in the wavelength range $6.2-8.0 \mu \mathrm{m}$ originated from the ${ }^{3} \mathrm{~F}_{3}$ energy level. 
The results of a related comprehensive experimental study of photoluminescence from multimode selenide-chalcogenide glass fibres co-doped with 500ppm $\mathrm{Pr}^{3+}$ and 500ppm of $\mathrm{Dy}^{3+}$ were reported in [35]. The study investigated how pumping wavelength affected the shape of the output spectrum. To achieve this co-doped fibre samples were illuminated at one end using pump lasers operating at $1.32 \mu \mathrm{m}, 1.511 \mu \mathrm{m}$ and $1.7 \mu \mathrm{m}$. The co-doped fibre exhibited photoluminescence spanning from $2 \mu \mathrm{m}$ to $6 \mu \mathrm{m}$. By varying the output power and wavelength of the pump sources, the spectral shape of the emitted luminescence could be modified to either reduce or enhance the contribution of radiation within a specific wavelength band. Results were compared against the photoluminescence from similar fibres doped with 1000ppm of $\operatorname{Pr}^{3+}$ and $1000 \mathrm{ppm}$ of $\mathrm{Dy}^{3+}$ and detailed photoluminescence lifetime measurements helped identify the important radiative transitions.

Lanthanide-doped chalcogenide glass MIR fibre lasers could deliver not only narrow-band sensing but could also provide new wavelengths for fibre laser surgery and act as the seed for broadband MIR supercontinuum sources. Extensive numerical modelling of lanthanide doped fibre lasers has been undertaken; some of our own earlier work in this area is summarised in [36] where numerical studies towards mid-infrared amplifier and laser action in rare earth doped chalcogenide glass doped with trivalent $\mathrm{Dy}$, $\mathrm{Pr}$ or $\mathrm{Tb}$ ions are described. These numerical models use rate equation are parameters such as absorption and emission cross-sections and transition lifetimes and branching ratios either obtained directly from experiments or derived from experimental measurements. Parameters like optimum fibre length, output power, optimum pump wavelength and pump power, fibre waveguide geometry and laser slope efficiency can be predicted.

A detailed experimental and numerical analysis of near-infrared and mid-infrared photoluminescence in a $\mathrm{Pr}^{3+}$-doped multi-phonon step-index chalcogenide-selenide glass fibre was carried out in [37].The numerical results not only agreed qualitatively with the experimental observations, but also allowed identification of the dominant electronic transitions contributing to the experimentally observed photoluminescence. Importantly, the numerical analysis made clear why the observed photoluminescent lifetime within the MIR wavelength range is shorter than that expected from Judd-Ofelt analysis. The numerical analysis showed that apart from the transition $\left({ }^{3} \mathrm{H}_{5} \rightarrow{ }^{3} \mathrm{H}_{4}\right)$ the transition $\left({ }^{3} \mathrm{~F}_{2},{ }^{3} \mathrm{H}_{6} \rightarrow{ }^{3} \mathrm{H}_{5}\right)$ also makes a significant contribution to MIR luminescence. Moreover, the numerical analysis was able to explain a twoexponent near-infrared luminescence decay experimentally observed at $\sim 2.5 \mu \mathrm{m}$ wavelength. It transpires that the photoluminescence observed in this wavelength range has contributions from two transitions with differing lifetimes: $\left({ }^{3} \mathrm{~F}_{4},{ }^{3} \mathrm{~F}_{3} \rightarrow{ }^{3} \mathrm{H}_{5}\right)$ and $\left({ }^{3} \mathrm{~F}_{2},{ }^{3} \mathrm{H}_{6} \rightarrow{ }^{3} \mathrm{H}_{4}\right)$.

In [38] the MIR emission behaviour of $\mathrm{Tb}^{3+}$ - doped Ge-As-Ga-Se bulk glasses $\left(500,1000\right.$, and $\left.1500 \mathrm{ppmw} \mathrm{Tb}^{3+}\right)$ and unstructured fibre (500 ppmw $\mathrm{Tb}^{3+}$ ) was investigated when pumping at $2.013 \mu \mathrm{m}$. A broad emission band was observed in the wavelength range 4.3-6.0 $\mu \mathrm{m}$, corresponding to a ${ }^{7} \mathrm{~F}_{5} \rightarrow{ }^{7} \mathrm{~F}_{6}$ transition. The observed emission lifetime was 12.9 $\mathrm{ms}$ at $4.7 \mu \mathrm{m}$. It was noted that the ${ }^{7} \mathrm{~F}_{4}$ level was depopulated non-radiatively, and so hence proposed that $\mathrm{Tb}^{3+}$-doped $\mathrm{Ge}$ As-Ga-Se fibre may operate as a quasi-three-level MIR fibre laser. Underlying glass-impurity vibrational absorption bands were numerically removed to give the true $\mathrm{Tb}^{3+}$ absorption cross section for Judd-Ofelt (JO) analysis. Numerical modelling of a three-level $\mathrm{Tb}^{3+}$-doped fibre laser with a $500 \mathrm{ppmw}$ doping level indicated the feasibility of an efficient three-level MIR fibre laser operating within 4.5-5.3 $\mu \mathrm{m}$, pumped at either 2.013 or 2.95 Further numerical analysis of spontaneous mid-infrared light emission from terbium ion doped multimode chalcogenide fibres was reported in [39] where numerical results and discuss the dependence of the output photoluminescence MIR power on the fibre loss, fibre length and pump wavelength. The models were extended in [40] to study the time-dynamics of the PL emitted by $\mathrm{Tb}^{3+}$ doped multimode chalcogenide-selenide fibres pumped at a wavelength of approximately $2 \mu \mathrm{m}$. Numerical results reproduced, and explained the origin of, discrepancies observed between PL decay curves obtained from different points along the fibre.

We also proposed a model for resonantly pumped $\mathrm{Pr}^{3+}$-doped chalcogenide fibre amplifiers, which includes excited state absorption and the full spectral amplified spontaneous emission spanning from $2 \mu \mathrm{m}$ to $6 \mu \mathrm{m}$ [41]. Based on this model, the observed near- and mid-infrared photoluminescence generated from $\mathrm{Pr}^{3+}$ - doped chalcogenide fibre was explained. The output of a $4.1 \mu \mathrm{m}$ resonantly pumped $\mathrm{Pr}^{3+}$ - doped chalcogenide fibre amplifier was simulated in both co- and counter-pumping schemes with results predicting that a $4.1 \mu \mathrm{m}$ counter-pumped fibre amplifier can achieve a power conversion efficiency (PCE) of over $62.8 \%$ for signal wavelengths ranging from $4.5 \mu \mathrm{m}$ to $5.3 \mu \mathrm{m}$. This modelling work 
was followed by the experimental observation of gain in a resonantly pumped $\mathrm{Pr}^{3+}$-doped chalcogenide glass midinfrared fibre amplifier, notwithstanding the signal excited-state absorption [42]. A maximum gain of $4.6 \mathrm{~dB}$ at a signal wavelength of $5.28 \mu \mathrm{m}$ was demonstrated in a $4.1 \mu \mathrm{m}$ resonantly pumped Pr3+-doped selenide-based chalcogenide glass fibre amplifier of length $109 \mathrm{~mm}$. Excited-stated absorption (ESA) at signal wavelengths around $5.5 \mu \mathrm{m}$ was also observed; this was attributed to the transition ${ }^{3} \mathrm{H}_{6} \rightarrow\left({ }^{3} \mathrm{~F}_{4},{ }^{3} \mathrm{~F}_{3}\right)$ after the pump ESA $\left({ }^{3} \mathrm{H}_{5} \rightarrow{ }^{3} \mathrm{H}_{6}\right)$ at a pump wavelength of $4.1 \mu \mathrm{m}$, which absorbs the MIR signal at wavelengths of 5.37, 5.51 and $5.57 \mu \mathrm{m}$, and so spoils the amplifier's performance at these wavelengths. This signal ESA should be suppressed in such a resonantly pumped $\operatorname{Pr}^{3+}$-doped selenide-based chalcogenide fibre amplifier.

The MIR ESA bands in trivalent praseodymium $\left(\mathrm{Pr}^{3+}\right)$ and terbium $\left(\mathrm{Tb}^{3+}\right)$ doped chalcogenide glass fibres and their interactions with photoluminescence (PL) emission bands have subsequently been further explored in hitherto unpublished work. This suggests that latent ESA bands can act as a depopulation mechanism for excited state energy levels, so making laser operation at specific wavelengths difficult or impossible. Whilst this indicates that 3- and 4-level laser systems proposed for these dopants may not be sufficient to faithfully model the PL behaviour, the characterisation of these ESA bands enables novel multi-wavelength excitation schemes to be proposed for laser operation at wavelengths which would otherwise be unusable.

High purity Ge-Sb-Se/S glasses prepared using a traditional melt-quench technique have also recently been investigated in Nottingham [43,44]. Following thermo-mechanical and refractive index measurements, mid-infrared (MIR) light guiding was demonstrated through an $8 \mathrm{~m}$ length of SIF with a $\mathrm{Ge}_{20} \mathrm{Sb}_{10} \mathrm{Se}_{70}$ at. \% core and $\mathrm{Ge}_{20} \mathrm{Sb}_{10} \mathrm{Se}_{67} \mathrm{~S}_{3}$ at. $\%$ cladding. Using a single distillation procedure, $\mathrm{Ge}_{20} \mathrm{Sb}_{10} \mathrm{Se}_{70}$ at. \%glass fibres showed a low optical loss across the 2 to $10 \mu \mathrm{m}$ wavelength range with the lowest baseline loss $0.44 \mathrm{~dB} / \mathrm{m}$ at $6.4 \mu \mathrm{m}$. Sm $\mathrm{Sm}^{3+}$ ions have been identified as a potential candidate for providing MIR sources at 3-4 $\mu \mathrm{m}$ and 6-8 $\mu \mathrm{m}$ wavelength regions [45]. Starecki et al. [46] reported emission from 6.5-8.5 $\mu \mathrm{m}$ from a 1000 ppmw Sm3+ doped $\mathrm{Ge}_{20} \mathrm{Sb}_{10} \mathrm{Se}_{65} \mathrm{Ga}_{5}$ atomic \% (at. \%) fibre although no lifetime measurements were reported for this long wavelength emission. Experimental photoluminescence and lifetimes at wavelengths including those beyond $7 \mu \mathrm{m}$ were recently reported by us in $\mathrm{Sm}^{3+}$ - doped selenide-chalcogenide glass fibres [47].

\section{SUMMARY}

Biomedical (and other) applications demand robust, high power, high efficiency, near diffraction limited broadband and narrowband sources, operating at mid- infrared (MIR) wavelengths. The spectral region from 1.5 to $12 \mu \mathrm{m}$ is of interest since it contains strong characteristic absorption peaks associated with the vibrational transitions of many important molecules. This paper has summarised some of the work at Nottingham aimed at developing such sources based on chalcogenide glass fibres. This includes the development and physical and optical characterization of chalcogenide glasses of high purity, supercontinuum sources based on step index chalcogenide glass fibres with high numerical aperture, bright luminescent sources and simulation and experimental work towards the MIR fibre-based lasers.

\section{REFERENCES}

[1] Baehr-Jones, T., Spott, A., Ilic, R., Spott, A., et al., Silicon-on-sapphire integrated waveguides for the midinfrared. Opt. Express 18(12), 12127-12135, 2010.

[2] Radosavljevic, S., Kuyken, B. and Roelkens, G., Efficient $5.2 \mu \mathrm{m}$ wavelength fiber-to-chip grating couplers for the Ge-on-Si and Ge-on-SOI mid-infrared waveguide platform. Opt. Express, 25(16), 19034- 19042, 2017.

[3] Penadés, J.S., Alonso-Ramos, C., et al., Suspended SOI waveguide with sub-wavelength grating cladding for mid-infrared. Opt. Letters, 39(19), 5661-5664, 2014.

[4] Hô, N., Phillips, M.C., Qiao, H., Allen, P.J., Krishnaswami, K., Riley, B. J., Myers, T.L., Norman C., Anheier, N.C., Single-mode low-loss chalcogenide glass waveguides for the mid-infrared, Opt. Lett. 31, 1860-1862, 2006.

[5] Seddon A. B., Pan W. J., Furniss D., Miller C. A., Rowe H., Zhang D. M., Mcbrearty E. M., Zhang Y., Loni A., Sewell P., Benson T. M., Fine embossing of chalcogenide glasses - A new fabrication route for photonic integrated circuits". Journal of Non-Crystalline Solids. 352 (23-25), 2515-2520. 2006. 
[6] Maes, F., Fortin, V., Poulain, S., Poulain, M., Carrée, J.-Y., Bernier, M., Vallée, R., Room-temperature fiber laser at $3.92 \mu \mathrm{m}$. , Optica 5, 761-764, 2018.

[7] Majewski, M.R., Woodward, R.I., Carreé, J.-Y., Poulain, S., Poulain, M., Jackson, S.D., Emission beyond $4 \mu \mathrm{m}$ and mid-infrared lasing in a dysprosium-doped indium fluoride (InF3) fiber. Opt. Lett 43, 1926-1929, 2018.

[8] Sanghera, J. S., Shaw, L. B., Pureza, P., Nguyen, V. Q., Gibson, D., Busse, L., Aggarwal, I. D., Florea, C. M. and Kung, F. H., Nonlinear properties of chalcogenide glass fibers,.International Journal of Applied Glass Science, 1, 296-308, 2010.

[9] Seddon, A.B., Tang, Z., Furniss, D., Sujecki S., Benson, T.M., Progress in rare-earth-doped midinfrared fiber lasers, Opt. Exp. 18(25), 26704-26719, 2010.

[10] Fang, Y., Furniss, D., Jayasuriya, D., Parnell, H., Tang, Z.Q., Gibson, D., Bayya, S., Sanghera, J., Seddon, A.B., Benson, T.M., Methods for determining the refractive indices and thermo-optic coefficients of chalcogenide glasses at MIR wavelengths. Optical Materials: X, 2, 100030, 2019.

[11]Bhowmick, K., Furniss, D., Morvan, H.P., Seddon A.B., Benson, T.M., Predictive, miniature co-extrusion of multilayered glass fiber-optic preforms, J Am Ceram Soc 99 (1) 106-114, 2016.

[12] Bhowmick, K., Morvan, H.P., Furniss, D., Seddon A.B., Benson, T.M., Co-extrusion of multilayer glass fiberoptic preforms: Prediction of layer dimensions in the extrudate. J Am Ceram Soc 96(1), 118-124, 2012.

[13] Alfano, R.R., The supercontinuum laser source: The ultimate white light, Springer, New York, 2016.

[14] Dudley, J.M., Taylor J. R., (Eds.) Supercontinuum generation in optical fibers. Cambridge University Press, 2010.

[15] Petersen, C.R., Møller, U., Kubat, I., Zhou, B., Dupont, S., Ramsay, J., Benson, T., Sujecki, S., Abdel-Moneim, N., Tang, Z., Furniss, D., Seddon, A., Bang O., Mid-infrared supercontinuum covering the 1.4-13.3 $\mu \mathrm{m}$ molecular fingerprint region using ultra-high NA chalcogenide step-index fibre. Nature Photonics, 8(11), 830$834,2014$.

[16] Jayasuriya, D., Petersen, C.R., Furniss, D., Markos, C., Tang, Z., Habib, M.S., Bang, O., Benson, T.M., Seddon, A.B., Mid-IR supercontinuum generation in birefringent, low loss, ultra-high numerical aperture Ge-As-Se-Te chalcogenide step-index fiber. Optical Materials Express, 9(6), pp.2617-2629, 2019.

[17] Jain D., Markos, C., Benson, T.M., Seddon, A., Bang, O., Exploiting dispersion of higher-order-modes using M-type fiber for application in mid-infrared supercontinuum generation" Scientific Reports 9:8536, 2019.

[18] Shaw, L. B., Cole, B., Thielen, P.A., Sanghera, J.S., Aggarwal, I.D., Mid-wave IR and long-wave IR laser potential of rare-earth doped chalcogenide glass fiber, IEEE Journal of Quantum Electronics, 37(9), 1127-1137, 2001 .

[19] Jackson, S., Towards high-power mid-infrared emission from a fibre laser, Nature Photonics, 6, 423-431, 2012.

[20] Dieke G. H., Crosswhite, H. M., The spectra of the doubly and triply ionized Rare Earths," Applied Optics, 2 (7), 675-686, 1963.

[21] Sakr, H., Furniss, D., Tang, Z., Sojka, L., Moneim, N.A., Barney, E., Sujecki, S., Benson, T.M., Seddon, A.B., Superior photoluminescence (PL) of $\mathrm{Pr}^{3+}-\mathrm{In}$, compared to $\mathrm{Pr}^{3+}-\mathrm{Ga}$, selenide-chalcogenide bulk glasses and PL of optically-clad fiber. Optics Express, 22(18), pp.21236-21252, 2014.

[22] Tang Z., Neate N. C., Furniss D., Sujecki S., Benson T. M., Seddon A. B. Crystallization behaviour of Dy ${ }^{3+}$ doped selenide glasses, Journal of Non-Crystalline Solids, DOI:10.1016/j.jnoncrysol.2010.11.065, 2010

[23] Cheng, Y., Tang, Z., Neate, N. C., Furniss, D., Benson, T.M., Seddon, A.B., The influence of dysprosium addition on the crystallization behavior of a chalcogenide selenide glass close to the fiber drawing temperature. Journal of the American Ceramic Society, 95(12), 3834-3841, 2012.

[24] Tang, Z., Furniss, D., Fay, M., Neate, N. C., Cheng, Y., Barney, E., Sojka, L., Sujecki, S., Benson, T.M., Seddon, A. B., First identification of rare-earth oxide nucleation in chalcogenide glasses and implications for fabrication of mid-infrared active fibers. Journal of the American Ceramic Society, 97 (2), 432-441, 2014. 
[25] Tang, Z., Furniss, D., Fay, M., Neate, N.C., Sujecki, S., Benson, T.M., Seddon, A.B., Crystallization and optical loss studies of $\mathrm{Dy}^{3+}$-doped, low Ga content, selenide chalcogenide bulk glasses and optical fibers, in Processing, Properties, and Applications of Glass and Optical Materials (The American Ceramic Society), 193-199, 2012.

[26] Tang, Z., Furniss, D., Fay, M., Sakr, H., Sójka, L., Neate, N., Weston, N., Sujecki, S., Benson, T.M., Seddon, A.B., Mid-infrared photoluminescence in small-core fiber of praseodymium-ion doped selenide-based chalcogenide glass. Optical Materials Express, 5(4), 870-886, 2015.

[27] Seddon, A.B., Furniss, D., Tang, Z.Q., Benson, T.M., Caspary, R. and Sujecki, S., True mid-infrared Pr ${ }^{3+}$ absorption cross-section in a selenide-chalcogenide host-glass. Proc. 18th International Conference on Transparent Optical Networks (ICTON) (pp. 1-6), 2016.

[28] Shiryaev, V.S., Karaksina, E.V., Kotereva, T.V., Churbanov, M.F., Velmuzhov, A.P., Nezhdanov, A.V., Special pure $\operatorname{Pr}(3+)$ doped $\mathrm{Ga}_{3} \mathrm{Ge}_{31} \mathrm{As}_{18} \mathrm{Se}_{48}$ glass for active mid-IR optics. J. Lumin. 209, 225-231, 2019.

[29] Sourková, P., Frumarova, B., Frumar, M., Nemec, P., Kincl, M., Nazabal, V., Moizan, V., Doualan, J.-L., Moncorgé, R, Spectroscopy of infrared transitions of $\mathrm{Pr}^{3+}$ ions in Ga-Ge-Sb-Se glasses. J. Lumin. 129, 1148$1153,2009$.

[30] Shiryaev, V. S., Karaksina, E. V., Kotereva, T. V., Churbanov, M. F., Velmuzhov, A. P., Sukhanov, M. V., Ketkova, L. A., Zernova, N. S., Plotnichenko, V. G., Koltashev, V. V., Preparation and investigation of $\operatorname{Pr}^{3+}{ }_{-}$ doped $\mathrm{Ge}-\mathrm{Sb}-\mathrm{Se}-\mathrm{In}-\mathrm{I}$ glasses as promising material for active mid-infrared optics, J. Lumin. 2017, 183, 129 $134,2017$.

[31] Ma,C., Guo,H., Xu,Y., Wu,Z., Li,M., Jia,X., Nie,Q., Effect of glass composition on the physical properties and luminescence of $\operatorname{Pr}^{3+}$ ion-doped chalcogenide glasses, J. Am. Ceram. Soc. 102, 6794-6801, 2019.

[32] Liu,Z., Bian,J., Huang,Y., Xu,T., Wang,X., Dai,S, Fabrication and characterization of mid-infrared emission of Pr3+ doped selenide chalcogenide glasses and fibres. RSC Adv. 7, 41520-41526, 2017.

[33] Bodiou, L., Starecki, F., Lemaitre, J., Nazabal, V., Doualan, J.-L., Baudet, E., Chahal, R., Gutierrez-Arroyo, A., Dumeige, Y., Hardy, I., Braud A., Mid-infrared guided photoluminescence from integrated Pr $^{3+}$-doped selenide ridge waveguides. Opt. Mater. 2018, 75, 109-115, 2018.

[34] Sojka, L., Tang, Z., Jayasuriya, D., Shen, M., Nunes, J., Furniss, D., Farries, M., Benson, T.M., Seddon, A.B. and Sujecki, S., 2020. Milliwatt-Level Spontaneous Emission Across the 3.5-8 $\mu \mathrm{m}$ Spectral Region from $\operatorname{Pr}^{3+}$ Doped Selenide Chalcogenide Fiber Pumped with a Laser Diode. Applied Sciences, 10(2), 539 doi:10.3390/app10020539 (11 pp), 2020.

[35] Sojka, L., Tang, Z., Jayasuriya, D., Shen, M., Furniss, D., Barney, E., Benson, T.M., Seddon, A.B., Sujecki, S., 2019. Ultra-broadband mid-infrared emission from a $\mathrm{Pr}^{3+} / \mathrm{Dy}^{3+}$ co-doped selenide-chalcogenide glass fiber spectrally shaped by varying the pumping arrangement. Optical Materials Express, 9(5), pp.2291-2306, 2019.

[36] Sojka, L., Benson, T.M., Furniss, D., Tang, Z., Sakr, H., Seddon, A.B., Sujecki, S., The modelling of fibre lasers for mid-infrared wavelengths, in Recent Trends in Computational Photonics, (ed.) Agrawal, A., Benson, T. M., DeLaRue, R., Wurtz, G.. Springer Nature, 2017.

[37] Sujecki, S., Sojka, L., Beres-Pawlik, E., Anders, K., Piramidowicz, R., Tang, Z., Furniss, D., Barney, E., Benson, T., Seddon, A., Experimental and numerical investigation to rationalize both near-infrared and midinfrared spontaneous emission in $\operatorname{Pr}^{3+}$ doped selenide chalcogenide fiber, Journal of Luminescence 209, 14-20, 2019.

[38] Sojka, L., Tang, Z., Furniss, D., Sakr, H., Fang, Y., Beres-Pawlik, E., Benson, T.M., Seddon, A.B., Sujecki, S., Mid-infrared emission in $\mathrm{Tb}^{3+}$-doped selenide glass fiber. JOSA B, 34(3), pp.A70-A79, 2017.

[39] Sujecki, S., Sojka, L., Pawlik, E., Anders, K., Piramidowicz, R., Tang, Z., Furniss, D., Barney, E., Benson, T., Seddon, A., Numerical analysis of spontaneous mid-infrared light emission from terbium ion doped multimode chalcogenide fibers. Journal of Luminescence, 199, 112-115, 2018. 
[40] Sujecki, S., Sojka, L., Tang, Z., Jayasuriya, D., Furniss, D., Barney, E., Benson, T., Seddon, A., Spatiotemporal modeling of mid-infrared photoluminescence from terbium (III) ion doped chalcogenide-selenide multimode fibers. Journal of Rare Earths, 37(11), 1157-1163, 2019.

[41] Shen, M., Furniss, D., Tang, Z., Barney, E., Sojka, L., Sujecki, S., Benson, T.M. and Seddon, A.B., 2018. Modeling of resonantly pumped mid-infrared $\operatorname{Pr}^{3+}$-doped chalcogenide fiber amplifier with different pumping schemes. Optics Express, 26(18), 23641-23660, 2018.

[42] Shen, M., Furniss, D., Farries, M., Jayasuriya, D., Tang, Z., Sojka, L., Sujecki, S., Benson, T.M., Seddon, A.B., Experimental observation of gain in a resonantly pumped Pr 3+-doped chalcogenide glass mid-infrared fibre amplifier notwithstanding the signal excited-state absorption. Scientific Reports 9(1), 1-8, 2019.

[43] Parnell, H., Furniss, D., Tang, Z., Neate, N. C., Benson, T. M. and Seddon, A. B., Compositional dependence of crystallization in $\mathrm{Ge}-\mathrm{Sb}-\mathrm{Se}$ glasses relevant to optical fiber making. Journal of the American Ceramic Society, 101(1), pp.208-219, 2018.

[44] Parnell, H., Furniss, D., Tang, Z., Fang, Y., Benson, T.M., Canedy, C.L., Kim, C.S., Kim, M., Merritt, C.D., Bewley, W.W., Vurgaftman, I., High purity Ge-Sb-Se/S step index optical fibers. Optical Materials Express, 9(9), pp.3616-3626, 2019.

[45] Walsh, B. M., Lee, H. R., Barnes, N.P., Mid-infrared lasers for remote sensing applications, J. Lumin. 169, 400-405, 2016.

[46] Starecki, F., Braud, A., Abdellaoui, N., Boussard-plédel, C., Bureau, B., Nazabal, V., 7 to $8 \mu \mathrm{m}$ emission from Sm3+ doped selenide fibers", Opt. Express 26, 26462-26469, 2018.

[47] Crane R. W., Sojka, L. Furniss, D., Nunes, J., Barney, E., Farries, M., Benson, T.M., Sujecki, S., Seddon, A.B., Experimental photoluminescence and lifetimes at wavelengths including beyond 7 microns in $\mathrm{Sm}^{3+}-\mathrm{doped}$ selenide-chalcogenide glass fibers, accepted for publication in Optics Express, 2020. 